\title{
Recent warming amplification over high elevation regions across the globe
}

\author{
Qixiang Wang $\cdot$ Xiaohui Fan $\cdot$ Mengben Wang
}

Received: 20 February 2013/Accepted: 16 July 2013/Published online: 31 July 2013

(C) The Author(s) 2013. This article is published with open access at Springerlink.com

\begin{abstract}
Despite numerous studies in recent decades, our understanding of whether warming amplification is prevalent in high-elevation regions remains uncertain. In this work, on the basis of annual mean temperature series (1961-2010) of 2,367 stations around the globe, we examine both altitudinal amplification and regional amplification in the high elevation regions across the globe using new methodology. We develop the function equations of warming components of altitude, latitude and longitude and station warming rates for individual stations within a high-elevation region based on basic mathematic and physical principles, and find a significant altitudinal amplification trend for the Tibetan Plateau, Loess Plateau, Yunnan-Guizhou Plateau, Alps, United States Rockies, Appalachian Mountains, South American Andes and Mongolian Plateau. At the same time, we detect a greater warming for four high-elevation regions than their low elevation counterparts for the paired regions available. These suggest that warming amplification in high-elevation regions is an intrinsic feature of recent global warming.
\end{abstract}

Keywords Surface air temperature - Elevation . Warming amplification · High-elevation region . Globe

\section{Introduction}

The patterns of climate variation in high-elevation regions may be substantially different from those derived from low

Q. Wang $\cdot$ X. Fan $\cdot$ M. Wang $(\bowtie)$

Institute of Loess Plateau, Shanxi University,

Taiyuan 030006, China

e-mail: mbwang@sxu.edu.cn elevation observations (Seidel and Free 2003). Hence characterization of climate change in high-elevation regions is of utmost interest for understanding the global climate change and for assessing the impacts of climate change on regional environments and economies (Beniston 2003). Against the background of the global average surface temperature increase (especially since about 1950) (Solomon et al. 2007), and the rapid retreat of mountain glaciers around the world (particularly in the Himalaya, Andes and Alps) (Solomon et al. 2007), huge efforts have been made to explore the features and impacts of climate change in high-elevation regions (Beniston et al. 1997; Beniston 2003; Rangwala and Miller 2012). However, despite numerous studies in the past decades (Beniston and Rebetez 1996; Diaz and Bradley 1997; Liu and Hou 1998; Liu and Chen 2000; Vuille and Bradley 2000; Pepin and Losleben 2002; Vuille et al. 2003; Pepin and Seidel 2005; Diaz and Eischeid 2007; Appenzeller et al. 2008; Pepin and Lundquist 2008; You et al. 2008, 2010; Liu et al. 2009; Lu et al. 2010), our understanding of whether elevationdependent warming commonly occurs in high-elevation regions, and whether high-elevation regions are warming faster than their low elevation counterparts, remains uncertain (Rangwala and Miller 2012).

While several studies reported positive evidence (Beniston and Rebetez 1996; Diaz and Bradley 1997; Liu and Hou 1998; Liu and Chen 2000; Liu et al. 2009), other studies found no evidence (Pepin and Seidel 2005; You et al. 2008; You et al. 2010) or even negative evidence (Vuille and Bradley 2000; Pepin and Losleben 2002; Lu et al. 2010) of elevation dependency in surface warming based on the surface observations, though most climate models have found enhanced warming in the high-elevation regions (Giorgi et al. 1997; Fyfe and Flato 1999; Snyder et al. 2002; Chen et al. 2003; Kotlarski et al. 2012). 
The elevation dependency was only statistically confirmed for the minimum temperature anomalies (1979-1993) in the Swiss Alps (Beniston and Rebetez 1996), while it was graphically displayed for minimum temperature (1951-1989) for the stations located in the latitudinal band $30^{\circ} \mathrm{N}-70^{\circ} \mathrm{N}$ (Diaz and Bradley 1997), and for mean and minimum temperature for the Tibetan Plateau and its surroundings as a whole (Liu and Chen 2000; Liu et al. 2009). However, it should be pointed out that no statistically significant altitudinal dependency of temperature increase has been demonstrated for either the Tibetan Plateau (You et al. 2008, 2010) or the Tibetan Plateau and its surroundings as a whole (Liu and Hou 1998).

This uncertainty is generally attributed to inadequacies in observations at high altitudes (Rangwala and Miller 2012; Ohmura 2012), data incompatibility (Ohmura 2012), methodological choices (Liu et al. 2009) and region-specific conditions (Beniston et al. 1997; Liu et al. 2009; Ohmura 2012). However there may be some fundamental aspects that have been overlooked. Although it is known that the warming is not only affected by altitude but also by latitude within a high-elevation region (Beniston and Rebetez 1996), few studies have considered the interacting effect of altitude and latitude on altitudinal amplification; and no studies have sought to separate out the altitudinal warming components from the warming rates at individual stations over the region. In this study we focus on the examination of both altitudinal amplification and regional amplification in the high elevation regions across the globe with new methodology based on annual mean temperature series (1961-2010) from 2,367 stations around the globe (Fig. 1).
We begin with analyzing the relationship between the station warming rates and station altitudes for the highelevation regions selected (Fig. 2; Table 1) using the simple linear regression method as in previous studies (Beniston and Rebetez 1996; You et al. 2008, 2010), and perform a brief attribution study on the mixed results from the analysis, with the aim of showing the necessity of the extraction of altitudinal warming components from the station warming rates for the detection of altitudinal amplification within a high-elevation region. We focus on the examination of altitudinal amplification in the eight high-elevation regions using the new function equations. At the same time, we employ a paired region comparison method to address the question whether high-elevation regions are warming faster than their low elevation counterparts.

\section{Data and methods}

\subsection{Data}

The raw data series consisted of $1,861,499,72$ and 25 station series from the quality controlled adjusted Global Historical Climatology Network monthly mean temperature dataset (GHCNM version 3) (Lawrimore et al. 2011); the daily mean air temperature data set of the National Meteorological Information Center of China (NMICC), the Historical Instrumental Climatological Surface Time Series of the Greater Alpine Region (HISTALP) (Auer et al. 2008), and MeteoSwiss, respectively. Each of the station series from the GHCNM (version 3), HISTALP and
Fig. 1 Distribution of 2,367 stations used for this study around the globe

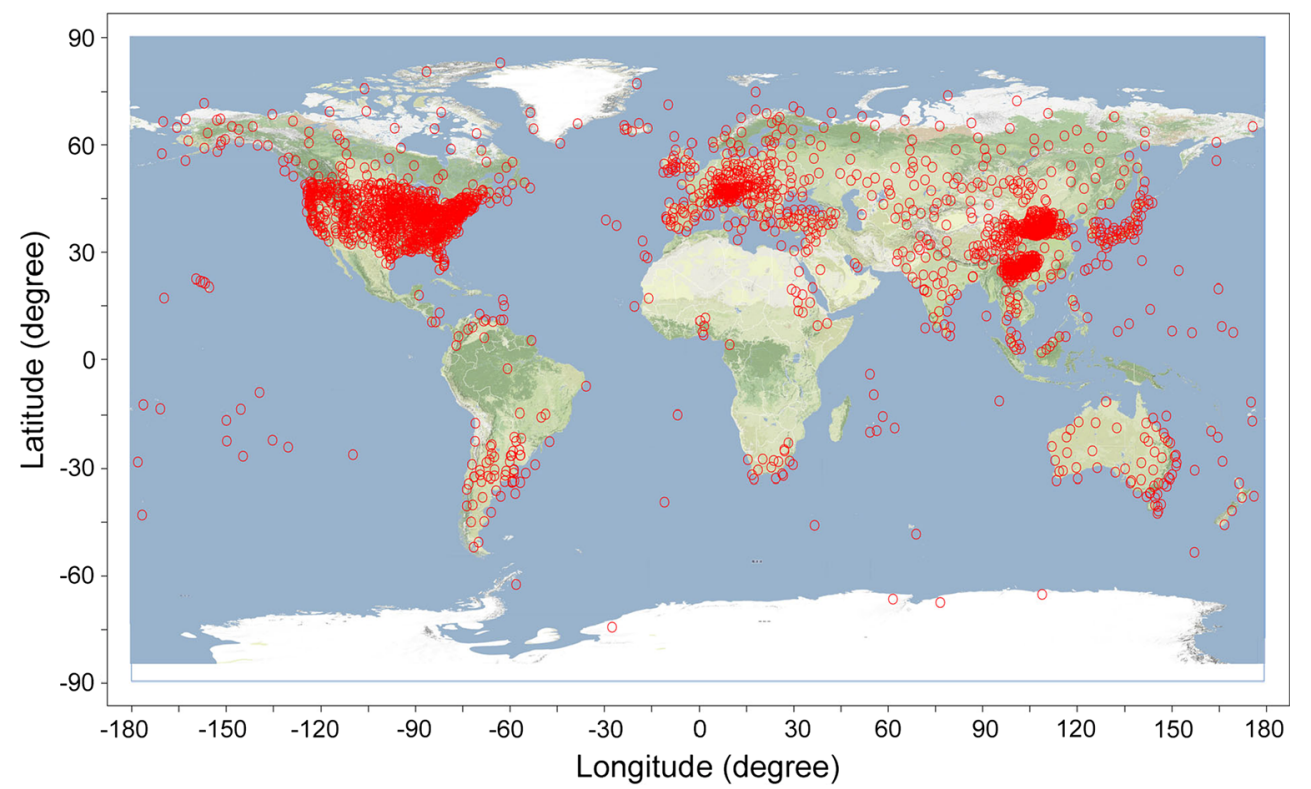


Fig. 2 Distribution of stations in the high-elevation regions shown across the globe. The typical high-elevation $(\geq 800 \mathrm{~m}$ abs), middle high-elevation $(\geq 500$ to $<800 \mathrm{~m}$ abs) and low high-elevation ( $\geq 200$ to

$<500 \mathrm{~m}$ abs) stations are shown in blue, green and red colors, respectively. Dots stand for significant positive trends, and circles indicates non-significant positive trends
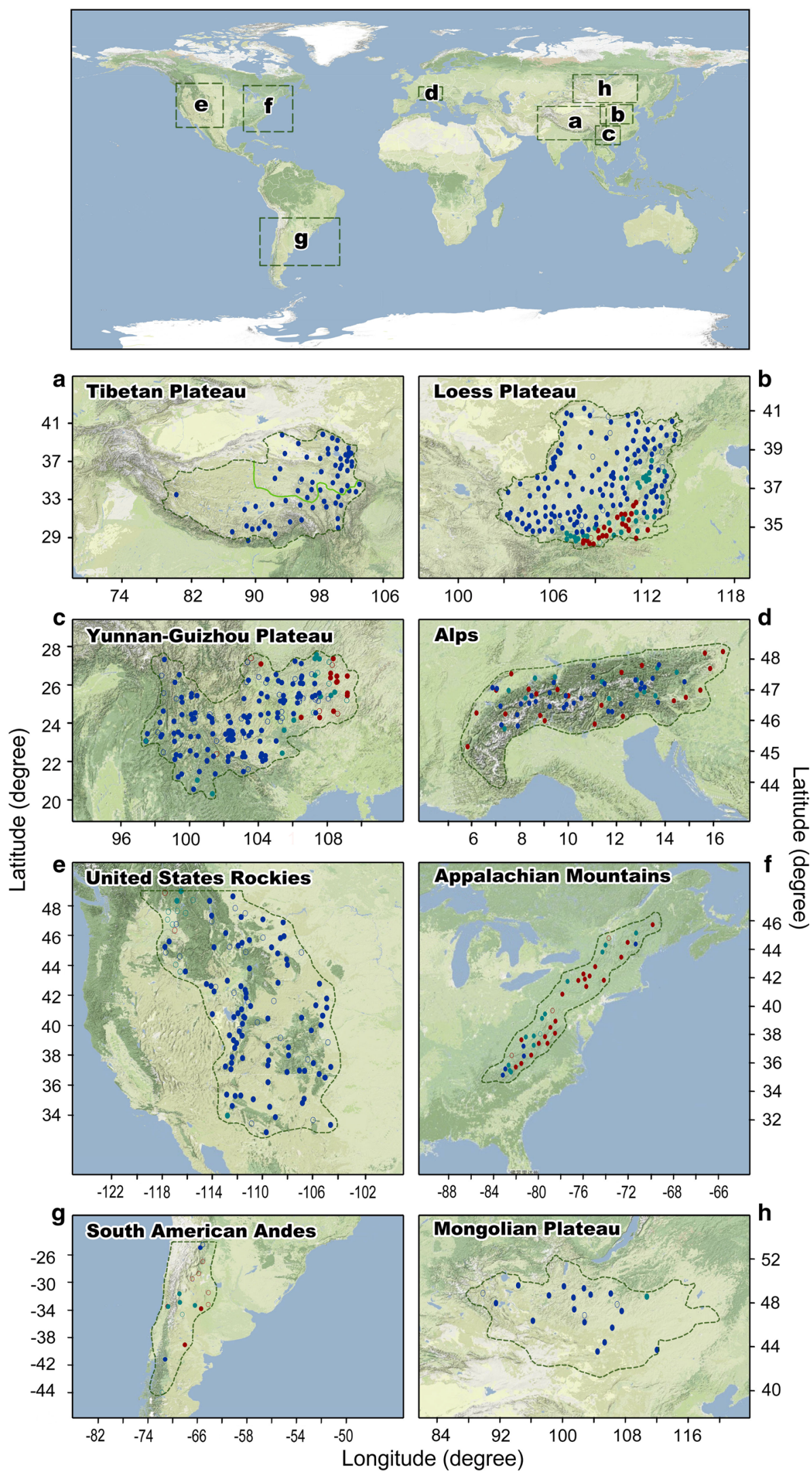
Table 1 Statistics of station mean, minimum and maximum values for altitude (in $\mathrm{km}$ ), latitude (in degree) and longitude (in degree) over the high-elevation regions across the globe

\begin{tabular}{|c|c|c|c|c|c|c|c|}
\hline No. & Region & Var. & Mean & Mini. & Max. & Dif. & $\mathrm{n}$ \\
\hline \multirow[t]{3}{*}{1} & \multirow[t]{3}{*}{ Tibetan Plateau } & Alt. & 3.4959 & 2.0857 & 4.700 & 2.6143 & 66 \\
\hline & & Lat. & 33.62 & 27.73 & 38.8 & 11.07 & \\
\hline & & Long. & 97.08 & 80.08 & 102.97 & 22.89 & \\
\hline \multirow[t]{3}{*}{2} & \multirow[t]{3}{*}{ Loess Plateau } & Alt. & 1.0452 & 0.3283 & 2.4280 & 2.0997 & 196 \\
\hline & & Lat. & 36.82 & 34.08 & 41.10 & 7.02 & \\
\hline & & Long. & 109.47 & 103.18 & 114.27 & 11.09 & \\
\hline \multirow[t]{3}{*}{3} & \multirow[t]{3}{*}{ Yunnan-Guizhou Plateau } & Alt. & 1.2971 & 0.2609 & 3.3190 & 3.0581 & 183 \\
\hline & & Lat. & 25.42 & 21.29 & 28.53 & 7.24 & \\
\hline & & Long. & 103.62 & 97.49 & 109.12 & 11.63 & \\
\hline \multirow[t]{3}{*}{4} & \multirow[t]{3}{*}{ Alps } & Alt. & 1.0501 & 0.2060 & 3.5800 & 3.3740 & 70 \\
\hline & & Lat. & 46.88 & 45.16 & 48.25 & 3.09 & \\
\hline & & Long. & 10.67 & 5.76 & 16.37 & 10.61 & \\
\hline \multirow[t]{3}{*}{5} & \multirow[t]{3}{*}{ United States Rockies } & Alt. & 1.4634 & 0.4237 & 2.7630 & 2.3393 & 117 \\
\hline & & Lat. & 41.51 & 32.82 & 49.00 & 16.18 & \\
\hline & & Long. & 111.14 & 104.49 & 117.88 & 13.39 & \\
\hline \multirow[t]{3}{*}{6} & \multirow[t]{3}{*}{ Appalachian Mountains } & Alt. & 0.5246 & 0.2057 & 1.9050 & 1.6993 & 42 \\
\hline & & Lat. & 39.55 & 35.05 & 45.66 & 10.61 & \\
\hline & & Long. & 78.13 & 69.81 & 83.19 & 13.38 & \\
\hline \multirow[t]{3}{*}{7} & \multirow[t]{3}{*}{ Andes } & Alt. & 0.5985 & 0.2650 & 1.2210 & 0.956 & 17 \\
\hline & & Lat. & 32.79 & 24.38 & 45.92 & 21.54 & \\
\hline & & Long. & 67.46 & 64.20 & 71.68 & 7.48 & \\
\hline \multirow[t]{3}{*}{8} & \multirow[t]{3}{*}{ Mongolian Plateau } & Alt. & 1.3895 & 0.7470 & 2.1810 & 1.434 & 20 \\
\hline & & Lat. & 47.44 & 43.58 & 49.65 & 6.07 & \\
\hline & & Long. & 102.21 & 89.93 & 111.90 & 21.97 & \\
\hline \multirow[t]{3}{*}{$1 \mathrm{a}$} & \multirow[t]{3}{*}{ North Tibetan Plateau } & Alt. & 3.2797 & 2.0900 & 4.6100 & 2.52 & 38 \\
\hline & & Lat. & 35.74 & 32.20 & 38.80 & 6.6 & \\
\hline & & Long. & 98.82 & 92.43 & 102.03 & 9.6 & \\
\hline \multirow[t]{3}{*}{$1 b$} & \multirow[t]{3}{*}{ South Tibetan Plateau } & Alt. & 3.7901 & 2.7360 & 4.7000 & 1.964 & 28 \\
\hline & & Lat. & 30.74 & 27.73 & 33.58 & 5.85 & \\
\hline & & Long. & 94.72 & 80.08 & 102.97 & 22.89 & \\
\hline
\end{tabular}

MeteoSwiss had at least 37 years of records (with 12 months of monthly mean temperature in each year) during the period 1961-2010, while each of the station series from the NMICC had 50-year records during the same period.

The annual data series for every station was established based on the monthly data from the GHCNM (version 3), while the annual data series for every station was directly from the HISTALP and MeteoSwiss. Because the monthly data from the GHCNM (version 3) have been quality controlled and adjusted, and the data from the HISTALP and MeteoSwiss have been homogenized, the annual data series derived from them were used for change trend test without further homogeneity test.

The overall quality of the data from the NMICC is fairly good, with nearly half of the temperature series having no missing data, and over $80 \%$ of data present for each temperature series that had missing data. The missing data mainly occurred in the early time (1962-1970) of the study period. The annual time series for each station was established based on two criteria: (1) a monthly value was calculated if no more than 3 day's data were missing in the month, and (2) an annual value was calculated if 12 months of monthly values were complete in the year. To eliminate the possible effect of artificial shifts caused by relocations of measurement sites or unknown reasons, each station time series of temperature was checked for homogeneity (Wang and Feng 2010; Wang et al. 2012). After rejecting 30 stations with inhomogeneous series, 469 stations were selected for trend test.

The trend slope was estimated using Sen method (Sen 1968), and the level of significance was tested non-parametric (Mann 1945; Kendall 1975) with an iterative procedure (Wang and Swail 2001). Of all the candidate 
stations, 55 of them have negative trends (whether significant or not), and 5 of them show no trend [Sen's slope $Q_{\text {TOTAL }}=0$ ] as in previous study (Fan et al. 2012). After rejecting the stations showing negative (cooling) trends or no trends, a total of 2,367 stations that have positive (warming) trends (whether significant or not) were finally selected for this study (Fig. 1): of which 1,808, 462, 72, and 25 stations are from the GHCNM (version 3), NMICC, HISTALP, and MeteoSwiss, respectively; and 970 are low lying stations $(<200 \mathrm{~m}$ abs) and 1397 are high-elevation stations ( $\geq 200 \mathrm{~m}$ ).

The exclusion of the stations showing negative trends is primarily due to the fact that the new function equations for the extraction of warming components of altitude, latitude and longitude ( $Q_{\mathrm{ALT}}, Q_{\mathrm{LAT}}$ and $Q_{\mathrm{LONG}}$, respectively) for individual stations are only applicable to warming trends (See next section for details). For the extraction of cooling components of altitude, latitude and longitude (- $Q_{\mathrm{ALT}}$, - $Q_{\mathrm{LAT}}$ and $-Q_{\mathrm{LONG}}$, respectively) from the cooling trends, three other function equations should be used (not shown). Besides, this exclusion should have no substantial influence on the results in this study, because 29 of them are low lying stations, and 26 of them are high-elevation stations, and only four of them are located in the eight high-elevation regions (two in the United States Rockies and other two in the Yunnan-Guizhou Plateau, accounting for 1.68 and $1.10 \%$ of the total stations, respectively). None are in the four paired high and low elevation regions.

\subsection{Computation of warming components}

Assume that the temperature $T$ is an intensive quantity (a single-valued, continuous and differentiable function of three-dimensional space), that is,

$T=T(x, y, z)$,

where $x, y$, and $z$ are the coordinates of the location of interest, then the derivative of temperature as a vector quantity can be defined as,

$T_{S D}=\left(\frac{\partial T}{\partial x}, \frac{\partial T}{\partial y}, \frac{\partial T}{\partial z}\right)$.

According to the Pythagorean theorem, the statement can be expressed as,

$\left|T_{S D}\right|=\sqrt{\left(\frac{\partial T}{\partial x}\right)^{2}+\left(\frac{\partial T}{\partial y}\right)^{2}+\left(\frac{\partial T}{\partial z}\right)^{2}}$.

Similarly, the warming rate $\left(Q_{\text {TOTAL }}\right)$ (magnitude of positive trend) at a station can be defined as,

$Q_{T O T A L}=\sqrt{Q_{A L T}^{2}+Q_{L A T}^{2}+Q_{L O N G}^{2}}$.
Corresponding to Eq. 4 for the station total warming rate $\left(Q_{\text {TOTAL }}\right)$, the total effect of altitude, latitude and longitude $\left(E_{\mathrm{TOTAL}}\right)$ can be defined as,

$$
\begin{aligned}
& E_{\text {TOTAL }} \\
& \quad=\sqrt{\left(E C_{A L T} \times A L T\right)^{2}+\left(E C_{L A T} \times L A T\right)^{2}+\left(E C_{L O N G} \times L O N G\right)^{2}},
\end{aligned}
$$

where $E C_{A L T} \times A L T, \quad E C_{L A T} \times L A T$ and $E C_{L O N G} \times$ $L O N G$ are the effects of altitude, latitude and longitude, respectively; in which $E C_{A L T}, E C_{L A T}$ and $E C_{L O N G}$ are the effect coefficients for altitude, latitude and longitude; and $A L T, L A T$ and $L O N G$ stand for altitude, latitude and longitude, respectively. Note that altitude $(A L T)$, latitude $(L A T)$ and longitude $(L O N G)$ are all expressed in kilometer $(\mathrm{km})$ here.

Since altitude is commonly expressed in meter, and latitude and longitude in degree,

$A L T=$ altitude $/ 1000$,

$L A T=$ latitude $\times 111.317$,

$L O N G=$ longitude $\times \pi \times R \times \cos ($ latitude $) / 180$,

where 111.317 (expressed in $\mathrm{km}$ ) is the distance constant for per degree of latitude, and $R$ is the radius of the earth. Because the distance between two degrees of longitude changes with latitude, the Eq. (8) is used.

According to Eqs. (4) and (5), the following relationships exist,

$$
\begin{aligned}
& \frac{Q_{A L T}}{Q_{T O T A L}} \\
& =\frac{E C_{A L T} \times A L T}{\sqrt{\left(E C_{A L T} \times A L T\right)^{2}+\left(E C_{L A T} \times L A T\right)^{2}+\left(E C_{L O N G} \times L O N G\right)^{2}}},
\end{aligned}
$$

$$
\begin{aligned}
& \frac{Q_{L A T}}{Q_{T O T A L}} \\
& =\frac{E C_{A L T} \times L A T}{\sqrt{\left(E C_{A L T} \times A L T\right)^{2}+\left(E C_{L A T} \times L A T\right)^{2}+\left(E C_{L O N G} \times L O N G\right)^{2}}}
\end{aligned}
$$

$$
\begin{aligned}
& \frac{Q_{L O N G}}{Q_{T O T A L}} \\
& =\frac{E C_{A L T} \times L O N G}{\sqrt{\left(E C_{A L T} \times A L T\right)^{2}+\left(E C_{L A T} \times L A T\right)^{2}+\left(E C_{L O N G} \times L O N G\right)^{2}}},
\end{aligned}
$$

That is, the ratio of altitudinal (latitudinal or longitudinal) warming component versus station total warming is equal to the ratio of altitudinal (latitudinal or longitudinal) effect versus the total effect. In other words, 
$Q_{A L T}=\frac{Q_{T O T A L} \times E C_{A L T} \times A L T}{\sqrt{\left(E C_{A L T} \times A L T\right)^{2}+\left(E C_{L A T} \times L A T\right)^{2}+\left(E C_{L O N G} \times L O N G\right)^{2}}}$,

$Q_{L A T}=\frac{Q_{T O T A L} \times E C_{L A T} \times L A T}{\sqrt{\left(E C_{A L T} \times A L T\right)^{2}+\left(E C_{L A T} \times L A T\right)^{2}+\left(E C_{L O N G} \times L O N G\right)^{2}}}$,

$Q_{L O N G}=\frac{Q_{\text {TOTAL }} \times E C_{L O N G} \times L O N G}{\sqrt{\left(E C_{A L T} \times A L T\right)^{2}+\left(E C_{L A T} \times L A T\right)^{2}+\left(E C_{L O N G} \times L O N G\right)^{2}}}$.

So the $Q_{\mathrm{ALT}}, Q_{\mathrm{LAT}}$ and $Q_{\mathrm{LONG}}$ can be separated out from the $Q_{\text {TOTAL }}$ at individual stations within a highelevation region using Eqs. 12, 13 and 14, respectively.

\subsection{Estimation of effect coefficients}

Besides the development of above functional equations, another crucial point for separating out $Q_{\mathrm{ALT}} \mathrm{S}$ from the $Q_{\text {TOTAL }}$ s at individual stations within a high-elevation region is to determine the $E C_{\mathrm{ALT}}, E C_{\mathrm{LAT}}$ and $E C_{\mathrm{LONG}}$ in the region. Here we define the $E C_{\mathrm{ALT}}, E C_{\mathrm{LAT}}$ and $E C_{\mathrm{LONG}}$ as the negative values of temperature gradients for altitude, latitude and longitude $\left(G_{\mathrm{ALT}}, G_{\mathrm{LAT}}\right.$ and $G_{\mathrm{LONG}}$, respectively).

To guide the estimation of $G_{\mathrm{ALT}}, G_{\mathrm{LAT}}$, and $G_{\mathrm{LONG}}$ within a high-elevation region, we first estimated the base $G_{\mathrm{ALT}}, G_{\mathrm{LAT}}$, and $G_{\mathrm{LONG}}$ on global scale. The base $G_{\mathrm{ALT}}$ was calculated based on the data from the 643 typical highelevation stations ( $\geq 800 \mathrm{~m}$ abs), where the noise (like the urbanization effect) is assumed to be small or negligible, while the base $G_{\mathrm{LAT}}$ and $G_{\mathrm{LONG}}$ were computed based on the data from the 970 low lying stations $(<200 \mathrm{~m} \mathrm{abs})$, where the altitudinal effect is negligible. The base $G_{\mathrm{ALT}}$,
$G_{\mathrm{LAT}}$ and $G_{\mathrm{LONG}}$ on the global scale and the $G_{\mathrm{ALT}}, G_{\mathrm{LAT}}$ and $G_{\mathrm{LONG}}$ for every region were estimated with the stepwise regression method based on the 50-year mean temperature and the station metadata (the absolute values of altitude, latitude and longitude) at the individual stations within a specific area: a latitude zonal band, longitude zonal band or a high-elevation region. Specifically, the base $G_{\mathrm{ALT}}$ was calculated for the latitude zonal bands in the Northern Hemisphere $(\mathrm{NH})\left(0-40^{\circ} \mathrm{N}\right.$ and $40-51^{\circ} \mathrm{N}$ for the west $\mathrm{NH}\left(0-180^{\circ} \mathrm{W}\right)$ and east $\mathrm{NH}\left(0-180^{\circ} \mathrm{E}\right)$, respectively) and in the Southern Hemisphere ( $\mathrm{SH})\left(0-45^{\circ} \mathrm{S}\right.$ for the $\mathrm{SH}$ as a whole), because the high-elevation stations selected are only distributed in the south of $51^{\circ} \mathrm{N}$ and the north of $45^{\circ} \mathrm{S}$, with 601 and 14 stations in the $\mathrm{NH}$ and $\mathrm{SH}$, respectively. The $G R_{\mathrm{ALT}}$ for the 754 middle elevation stations (from $\geq 200$ to $<800 \mathrm{~m}$ abs) was also computed for the $\mathrm{NH}$ and $\mathrm{SH}$, respectively. The base $G_{\mathrm{LAT}}$ was estimated for the latitude zonal bands $\left(0-20^{\circ} \mathrm{N}, 20-40^{\circ} \mathrm{N}, 40-60^{\circ} \mathrm{N}\right.$ and $60-85^{\circ} \mathrm{N}$; and $0-20^{\circ} \mathrm{S}, 20-40^{\circ} \mathrm{S}, \quad 40-60^{\circ} \mathrm{S}$ and $\left.60-80^{\circ} \mathrm{S}\right)$, while the base $G_{\mathrm{LONG}}$ was estimated for the longitude zonal bands $\left(0-90^{\circ} \mathrm{W}, 90-180^{\circ} \mathrm{W}, 0-90^{\circ} \mathrm{E}\right.$, 90- $180^{\circ} \mathrm{E}$ for the $\mathrm{NH}$ and $\mathrm{SH}$, respectively).

\section{Relationship between station warming rates and station altitudes}

Our analysis shows that a significant warming trend is found for all the eight regions tested, with the greatest warming in the Tibetan Plateau, and the weakest in Yunnan-Guizhou Plateau (Table 2). However, mixed relationships between station warming rates $\left(Q_{\mathrm{TOTAL}} \mathrm{s}\right)$ and station altitudes are detected among these regions, with significant altitude amplification of $Q_{\text {TOTAL }} \mathrm{S}$ in three regions, but no altitude amplification of $Q_{\text {TOTAL }}$ in five regions (Table 3 ).

Table 2 Monotonic trends of annual mean temperature during 1961-2010 over the high-elevation regions across the globe

\begin{tabular}{|c|c|c|c|c|c|c|}
\hline \multirow[t]{2}{*}{ No. } & \multirow[t]{2}{*}{ Region } & \multicolumn{3}{|c|}{ Mann-Kendall test } & \multirow[t]{2}{*}{ Tmean $\left({ }^{\circ} \mathrm{C}\right)$} & \multirow[t]{2}{*}{$\mathrm{n}$} \\
\hline & & $Z$ & $p$ & $Q_{\text {TOTAL }}(\times 50)$ & & \\
\hline 1 & Tibetan Plateau & 5.749 & $<0.001$ & 1.867 & 1.608 & 66 \\
\hline 2 & Loess Plateau & 4.525 & $<0.001$ & 1.595 & 9.074 & 196 \\
\hline 3 & Yunnan-Guizhou Plateau & 3.491 & $<0.001$ & 0.779 & 15.602 & 183 \\
\hline 4 & Alps & 4.465 & $<0.001$ & 1.639 & 6.220 & 70 \\
\hline 5 & United States Rockies & 4.015 & $<0.001$ & 1.321 & 8.549 & 117 \\
\hline 6 & Appalachian Mountains & 3.077 & $=0.002$ & 1.754 & 9.547 & 42 \\
\hline 7 & South American Andes & 3.723 & $<0.001$ & 1.353 & 15.829 & 17 \\
\hline 8 & Mongolian Plateau & 2.711 & $=0.008$ & 1.858 & 0.882 & 20 \\
\hline $1 \mathrm{a}$ & Northern Tibetan Plateau & 5.387 & $<0.001$ & 1.955 & 0.551 & 38 \\
\hline $1 b$ & Southern Tibetan Plateau & 5.525 & $<0.001$ & 1.847 & 3.044 & 28 \\
\hline
\end{tabular}

Trend magnitude $\left(Q_{\text {TOTAL }}\right)$ is expressed in ${ }^{\circ} \mathrm{C}$ per 50 years. Two-tailed $p$ value is given. The significant $Z$, judged using $95 \% \mathrm{CI}$, are set in bold Tmean stands for 50 -year average temperature 
Table 3 Relationships between station warming rates and station altitudes in the high-elevation regions across the globe

\begin{tabular}{|c|c|c|c|c|c|c|}
\hline \multirow[t]{2}{*}{ No. } & \multirow[t]{2}{*}{ Region } & \multicolumn{4}{|c|}{ Simple linear regression } & \multirow[t]{2}{*}{$\mathrm{n}$} \\
\hline & & $r$ & $p$ & $Q_{\mathrm{AMP}}$ & $B$ & \\
\hline 1 & Tibetan Plateau & 0.027 & $=0.830$ & 0.027 & 1.761 & 66 \\
\hline 2 & Loess Plateau & 0.280 & $<0.001$ & 0.394 & 1.175 & 196 \\
\hline 3 & $\begin{array}{l}\text { Yunnan-Guizhou } \\
\text { Plateau }\end{array}$ & 0.287 & $<0.001$ & 0.224 & 0.502 & 183 \\
\hline 4 & Alps & -0.119 & $=0.327$ & -0.062 & 2.096 & 70 \\
\hline 5 & $\begin{array}{l}\text { United States } \\
\text { Rockies }\end{array}$ & 0.287 & $=0.002$ & 0.229 & 0.404 & 117 \\
\hline 6 & $\begin{array}{c}\text { Appalachian } \\
\text { Mountains }\end{array}$ & 0.051 & $=0.746$ & 0.070 & 1.327 & 42 \\
\hline 7 & $\begin{array}{l}\text { South American } \\
\text { Andes }\end{array}$ & 0.037 & $=0.888$ & 0.068 & 0.612 & 17 \\
\hline 8 & $\begin{array}{l}\text { Mongolian } \\
\text { Plateau }\end{array}$ & -0.008 & $=0.972$ & -0.013 & 1.170 & \\
\hline $1 \mathrm{a}$ & $\begin{array}{l}\text { Northern Tibetan } \\
\text { Plateau }\end{array}$ & -0.079 & $=0.635$ & -0.087 & 2.252 & \\
\hline $1 b$ & $\begin{array}{l}\text { Southern Tibetan } \\
\text { Plateau }\end{array}$ & 0.617 & $<0.001$ & 0.610 & -0.613 & \\
\hline
\end{tabular}

$Q_{\text {AMP }}$ denotes warming amplification rate with altitude, expressed in ${ }^{\circ} \mathrm{C}$ per 50 years per $\mathrm{km}$ of altitude. Pearson correlation coefficient $(r)$ is given with the two-tailed $p$ value for each case. The significant coefficients, judged using $95 \% \mathrm{CI}$, are set in bold
It is noteworthy that a significant altitude amplification of $Q_{\text {TOTAL }}$ s is detected in the Southern Tibetan Plateau but not in the Northern Tibetan Plateau (Table 3) when we divide the entire Tibetan Plateau into these two sub-regions along the dividing ridges of Tanggula Mountains and east Bayan Har Mountains.

In high-elevation regions temperature change depends strongly on altitude, latitude and longitude (Beniston and Rebetez 1996). Due to the effects of these three factors, especially the positive effects of altitude and latitude, on temperature change in the high-elevation regions tested (See next section for details), the mixed results could be attributed to region-specific interactions between altitude and latitude (positive, negative or no interaction) and the relative magnitudes of altitude and latitude effects (comparable to each other or one is much larger than the other) across these regions. As exemplified by the Tibetan Plateau and the Loess Plateau, a significant negative spatial correlation between the station altitudes and station latitudes (SCOALLA) is detected across the Tibetan Plateau, whereas a significant positive SCOALLA is observed in the Loess Plateau (Fig. 3). This indicates that the altitude effect could be cancelled out over the former but enhanced over the latter by the latitude effect. Therefore the altitude
Fig. 3 Exemplification of the effect of SCOALLA on altitudinal dependency of station warming rates in the high-elevation regions. SCOALLA indicates spatial correlation between station's altitudes and station's latitudes as shown in the left panels for the Tibetan Plateau, Loess Plateau, Northern Tibetan Plateau, and Southern Tibetan Plateau, respectively. The altitudinal dependency of station warming rates is shown in the right panels for the related regions, respectively. Pearson correlation coefficients $(r)$ are shown with two-tailed $p$ values in parentheses. The significant coefficients, judged using $95 \% \mathrm{CI}$, are set in bold
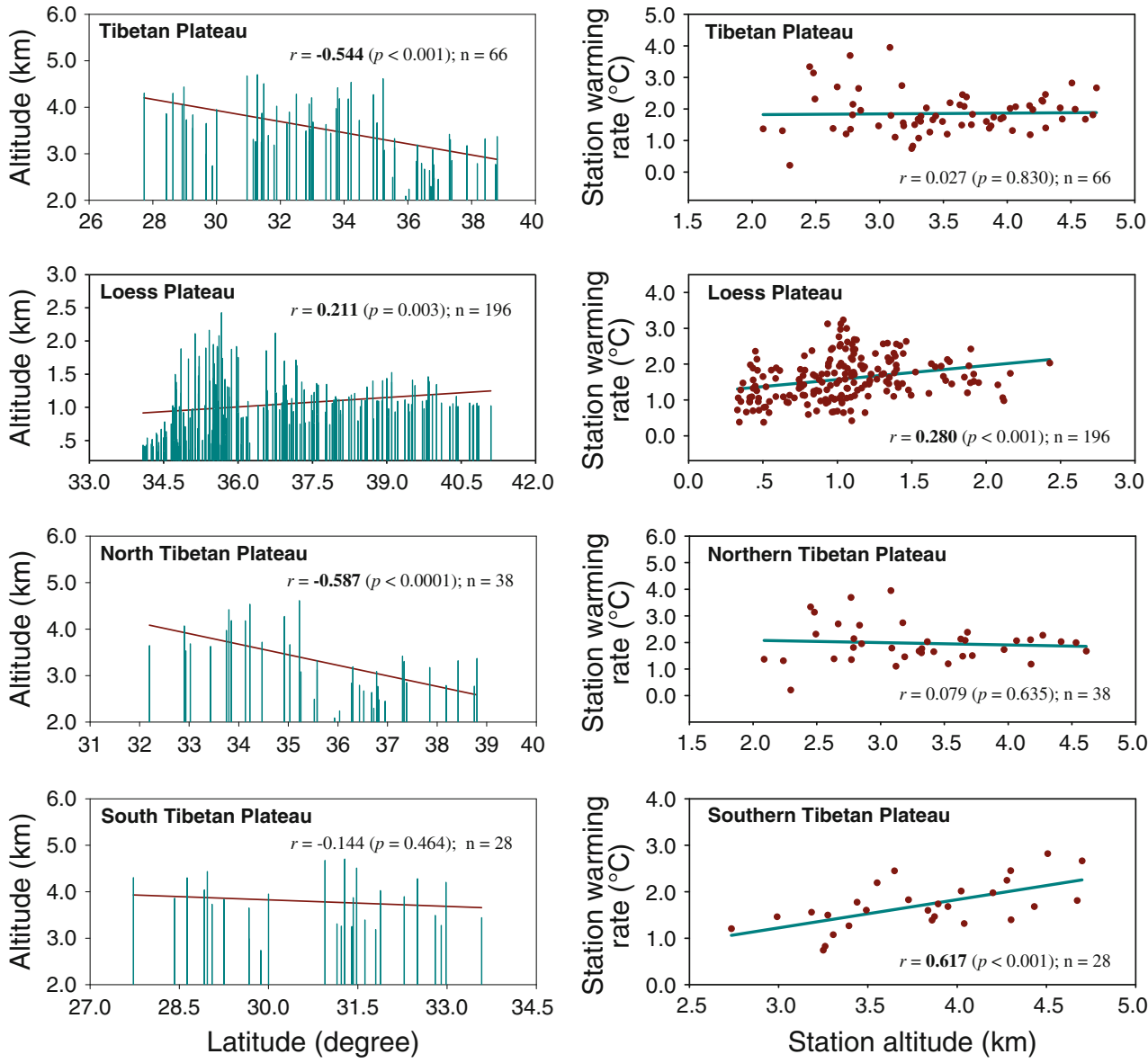
amplification of $Q_{\text {TOTAL }}$ s can be detected within the latter but not within the former. At the same time, a significant negative SCOALLA occurs across the Northern Tibetan Plateau (as in the entire Tibetan Plateau), whereas no significant SCOALLA appears across the Southern Tibetan Plateau (Fig. 3). This suggests that the altitude effect could be cancelled out over the Northern Tibetan Plateau (as in the entire Tibetan Plateau) while no obvious correlation between altitude and latitude exists across the Southern Tibetan Plateau. Hence the altitude amplification of $Q_{\text {TO- }}$ ${ }_{T A L} S$ can not be detected for the Northern Tibetan Plateau either while an altitude amplification of $Q_{\text {TOTAL }}$ s has been observed for the Southern Tibetan Plateau. Nevertheless, as long as the total warming rates $\left(Q_{\text {TOTAL }} \mathrm{s}\right)$ are involved, altitude amplification cannot be detected in any high-elevation region, except by chance. The separation of altitudinal components from the warming rates at individual stations is therefore a prerequisite for a precise analysis of altitudinal amplification within a high-elevation region.

\section{Altitudinal warming amplification}

With the $Q_{\mathrm{TOTAL}} \mathrm{S}$ at individual stations, and the $E C_{\mathrm{ALT}}$, $E C_{\mathrm{LAT}}$ and $E C_{\mathrm{LONG}}$ for every region (Table 4), we perform the extraction of $Q_{\mathrm{ALT}}\left(Q_{\mathrm{LAT}}\right.$ or $\left.Q_{\mathrm{LONG}}\right)$ from $\mathrm{Q}_{\mathrm{TOTAL}}$ for every station within each region using the functional equation(s) for them. As a result, we find a highly significant altitude amplification trend for all the regions except for the Mongolian Plateau, where a marginally significant altitude amplification trend is detected (Fig. 4). When the two sub-regions of the Tibetan Plateau are considered together, the greatest amplification appears in the Southern Tibetan Plateau while the weakest in the Mongolian Plateau among these regions. The averaged 50-year trend of $0.19( \pm 0.09)[\text { mean }( \pm \mathrm{SD})]^{\circ} \mathrm{C}$ per $\mathrm{km}$ of altitude is found for the eight regions. Note that if the small amplification trend in the Mongolian Plateau is set aside, the average amplification rate will be slightly greater $\left[0.21( \pm 0.08){ }^{\circ} \mathrm{C}\right.$ per $\mathrm{km}$ of altitude]. Judged from the averaged warming components of altitude, latitude and longitude ( $Q_{\text {ALTAV }}$, $Q_{\text {LATAV }}$, and $Q_{\text {LONGAV }}$, respectively) in the eight regions (Table 5), the relative contributions of altitude, latitude and longitude account for $13.5( \pm 7.8) \%, 72.9( \pm 23.4) \%$ and $13.6( \pm 20.9) \%$, respectively.

The altitude warming amplification in the high-elevation regions is consistent with the modeled and observed warming amplification in the free troposphere (Santer et al. 2005; Thorne et al. 2011), indicating a decrease of the surface mean temperature lapse rate over the last 50 years, consistent with the model results (Santer et al. 2005; Kotlarski et al. 2012). The fact that the upward shift in the height of the freezing level surface and hence the significant decline of snow covered area in the mountainous regions (Diaz et al. 2003; Bradley et al. 2009) could be a result of the altitude warming amplification within these regions. Compared with altitude, latitude has much lager contribution to the sum of $Q_{\mathrm{ALTAV}}, Q_{\mathrm{LATAV}}$ and $Q_{\mathrm{LONGAV}}$ in every high-elevation region (Table 5), suggesting a greater effect from latitude than altitude. This verifies that

Table 4 Effect coefficients of altitude, latitude and longitude in the high elevation regions across the globe

\begin{tabular}{|c|c|c|c|c|c|c|}
\hline No. & Region & $\begin{array}{l}E C_{\mathrm{ALT}} \\
\left({ }^{\circ} \mathrm{C} \text { per km }\right)\end{array}$ & $\begin{array}{l}E C_{\mathrm{LAT}} \\
\left({ }^{\circ} \mathrm{C} \text { per degree }\right)\end{array}$ & $\begin{array}{l}E C_{\mathrm{LAT}} \\
\left({ }^{\circ} \mathrm{C} \text { per km }\right)\end{array}$ & $\begin{array}{l}E C_{\mathrm{LONG}} \\
\left({ }^{\circ} \mathrm{C} \text { per degree }\right)\end{array}$ & $\begin{array}{l}E C_{\mathrm{LONG}} \\
\left({ }^{\circ} \mathrm{C} \text { per } \mathrm{km}\right)\end{array}$ \\
\hline 1 & Tibetan Plateau & 6.0596 & 1.0083 & 0.0091 & 0.1177 & 0.0013 \\
\hline 2 & Loess Plateau & 4.8945 & 0.5049 & 0.0045 & 0.1512 & 0.0017 \\
\hline 3 & Yunnan-Guizhou Plateau & 3.9007 & 0.7496 & 0.0067 & 0.2452 & 0.0024 \\
\hline 4 & Alps & 5.4186 & 0.9956 & 0.0089 & 0 & 0 \\
\hline 5 & United States Rockies & 5.7474 & 0.6666 & 0.0060 & 0 & 0 \\
\hline 6 & Appalachian Mountains & 5.7996 & 1.0216 & 0.0092 & 0 & 0 \\
\hline 7 & South American Andes & 6.0953 & 0.6755 & 0.0061 & 0 & 0 \\
\hline 8 & Mongolian Plateau & 2.1065 & 0.8345 & 0.0075 & 0 & 0 \\
\hline $1 \mathrm{a}$ & Northern Tibetan Plateau & 6.5443 & 1.1527 & 0.0104 & 0.2523 & 0.0028 \\
\hline $1 b$ & Southern Tibetan Plateau & 5.5027 & 0.9860 & 0.0089 & 0 & 0 \\
\hline $\mathrm{S} 1$ & Northern Polar Area (north of $60^{\circ} \mathrm{N}$ ) & 0 & 0.8525 & 0.0077 & 0.0616 & 0.0013 \\
\hline $\mathrm{S} 2$ & High Latitude Area $\left(55-60^{\circ} \mathrm{N}\right)$ & 0 & 0.9066 & 0.0081 & 0.0424 & 0.0007 \\
\hline
\end{tabular}

Effect coefficients of altitude, latitude and longitude $\left(E C_{\mathrm{ALT}}, E C_{\mathrm{LAT}}\right.$, and $E C_{\mathrm{LONG}}$, respectively) are the corresponding negative values of temperature gradients of altitude, latitude and longitude $\left(G_{\mathrm{ALT}}, G_{\mathrm{LAT}}\right.$, and $G_{\mathrm{LONG}}$, respectively). The $G_{\mathrm{ALT}}, G_{\mathrm{LAT}}$, and $G_{\mathrm{LONG}}$ are estimated using stepwise regression (see Sect. 2.3 for details). However, when a variable can not be introduced, i.e. the partial correlation coefficient for it is not significant (judged using $95 \% \mathrm{CI}$ ), its effect coefficient will be considered to be zero. Hence the $E C_{\mathrm{ALT}}\left(E C_{\mathrm{LONG}}\right)$ is zero for some regions tested 
Fig. 4 Relationships between altitudinal warming rates and station altitudes in the high elevation regions across the globe. Dots represent altituderelated warming rates $\left({ }^{\circ} \mathrm{C}\right.$ per 50-year), and dark cyan lines indicate linear regression lines. Pearson correlation coefficients $(r)$ are shown with two-tailed $p$ values in parentheses. The significant coefficients, judged using $95 \% \mathrm{CI}$, are set in bold, with the marginally significant coefficient in italic bold
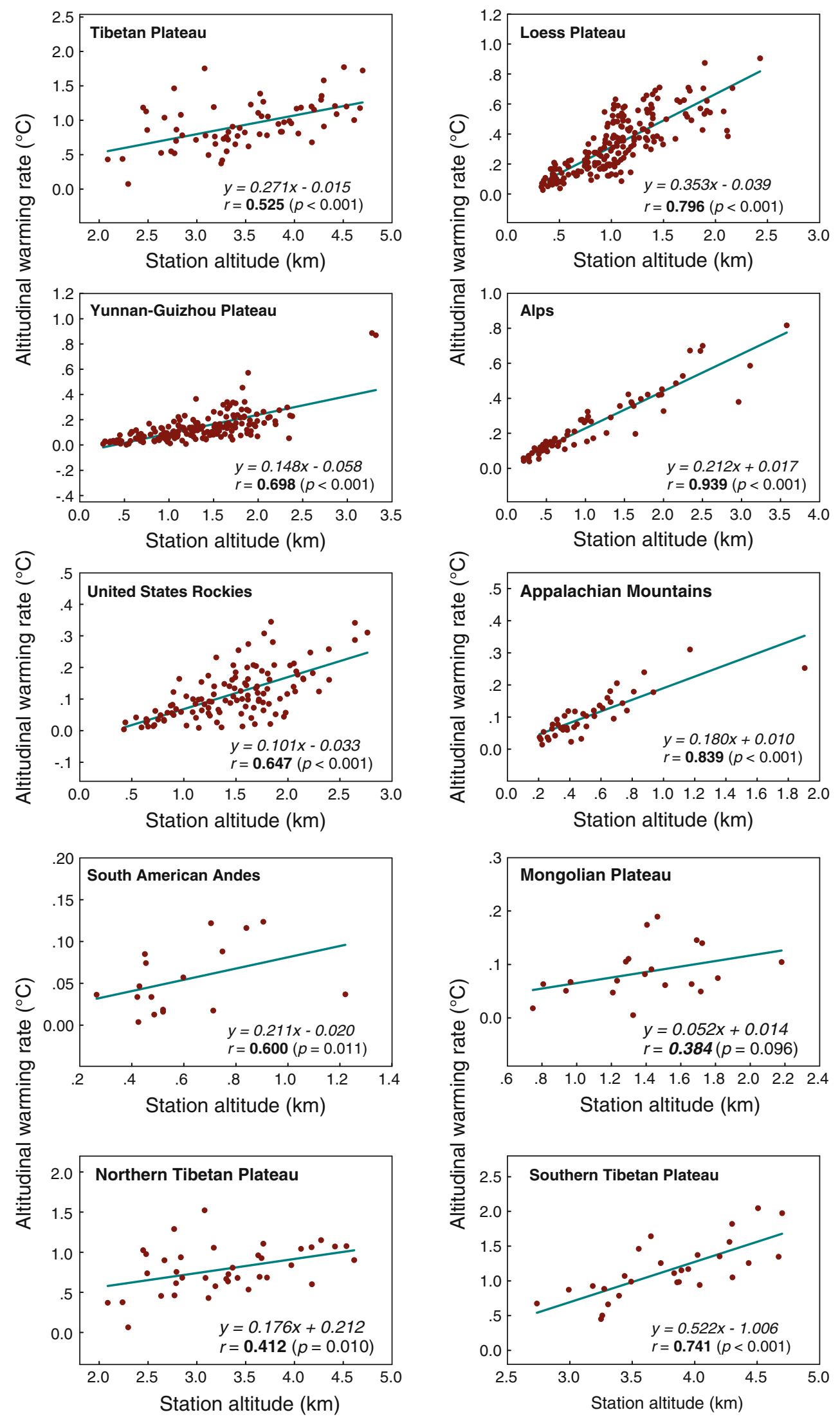
Table 5 Average warming components for altitude, latitude and longitude over the high-elevation regions across the globe

\begin{tabular}{|c|c|c|c|c|c|c|c|}
\hline No. & Region & $Q_{\text {ALTAV }}$ & $\%$ & $Q_{\text {LATAV }}$ & $\%$ & $Q_{\text {LONGAV }}$ & $\%$ \\
\hline 1 & Tibetan Plateau & 0.932 & 31.6 & 1.506 & 51.0 & 0.512 & 17.4 \\
\hline 2 & Loess Plateau & 0.330 & 13.1 & 1.157 & 46.1 & 1.025 & 40.8 \\
\hline 3 & Yunnan-Guizhou Plateau & 0.135 & 11.0 & 0.468 & 38.2 & 0.622 & 50.8 \\
\hline 4 & Alps & 0.240 & 10.7 & 2.009 & 89.3 & 0 & 0 \\
\hline 5 & United States Rockies & 0.115 & 13.7 & 0.729 & 86.3 & 0 & 0 \\
\hline 6 & Appalachian Mountains & 0.104 & 7.1 & 1.358 & 92.9 & 0 & 0 \\
\hline 7 & South American Andes & 0.106 & 14.1 & 0.642 & 85.9 & 0 & 0 \\
\hline 8 & Mongolian Plateau & 0.085 & 6.9 & 1.148 & 93.1 & 0 & 0 \\
\hline $1 \mathrm{a}$ & Northern Tibetan Plateau & 0.789 & 24.3 & 1.538 & 47.3 & 0.927 & 28.5 \\
\hline $1 b$ & Southern Tibetan Plateau & 1.152 & 48.0 & 1.245 & 52.0 & 0 & 0 \\
\hline S1 & Northern Polar Area (North of $60^{\circ} \mathrm{N}$ ) & 0 & 0 & 1.752 & 91.8 & 0.157 & 8.2 \\
\hline S2 & High Latitude Area $\left(55-60^{\circ} \mathrm{N}\right)$ & 0 & 0 & 3.223 & 94.6 & 0.183 & 5.4 \\
\hline
\end{tabular}

$Q_{\mathrm{ALTAV}}, Q_{\mathrm{LATAV}}$ and $Q_{\mathrm{LONGAV}}$ represent average warming components for altitude, latitude and longitude, respectively. They are computed from the $Q_{\mathrm{ALT}} \mathrm{S}, Q_{\mathrm{LAT}} \mathrm{S}$ and $Q_{\mathrm{LONG}} \mathrm{S}$ at the stations within a region, and expressed in ${ }^{\circ} \mathrm{C}$ per 50 years. The percentage $(\%)$ is the value relative to the sum of $Q_{\text {Altav }}, Q_{\text {Latav }}$ and $Q_{\text {LONGav }}$

the effect of the positive or negative SCOALLA on the altitudinal dependence of station warming rates (Fig. 3) is closely associated with the latitude effect. Although the longitudinal effect is not significant in over half of the regions, it does occur in the Tibetan Plateau, Loess Plateau and Yunnan-Guizhou Plateau. The magnitudes of longitude effect in these three plateaus (Table 5) coincide inversely with their distances (about 1,200, 800 and $500 \mathrm{~km}$, respectively) to the Pacific Ocean in the southeast. This suggests that the longitude effect in these three regions is to some extent negatively linked to their distance from the ocean under the condition of strong southeast summer monsoon and northwest winter monsoon in China.

\section{Regional warming amplification}

The analysis of temperature trends for the paired regions shows that the warming for the sampled North Tibetan Plateau, East Loess Plateau, Southeast Rockies and Alps is clearly greater than their low-lying counterparts (Fig. 5; Table 6). It is noteworthy that the warming for the sampled North Tibetan Plateau is also much greater than the North China Plain (both of which are located at the same latitudes as well). The warming is also much greater over the sampled North Tibetan Plateau than those for the Southeast Rockies (USA), Alps, East lower region of SE Rockies, and East lower region of Alps, even if the latter are located at higher latitudes than the former (though at very different longitudes) (Table 6). In addition, the warming over the Southern Tibetan Plateau is much greater than the Loess Plateau though the former is located at lower latitudes than the latter, and, similarly, the warming over the Northern
Tibetan Plateau is greater than the Mongolian Plateau (Table 3). These results suggest that the warming in a highelevation region is usually greater than its lower elevation counterpart(s) at the same latitudes or even those at the somewhat higher latitudes.

\section{Discussion}

The altitude temperature gradient $\left(G_{\mathrm{ALT}}\right)$ in a high-elevation region is dominated by the height temperature gradient $\left(G_{\mathrm{H}}\right)$ in the free troposphere, and modulated by local conditions. The $G_{\mathrm{ALT}}$ and $G_{\mathrm{H}}$ typically change between about $-9.8{ }^{\circ} \mathrm{C}$ per $\mathrm{km}$ (the dry adiabatic lapse rate) and about $-4.0^{\circ} \mathrm{C}$ per $\mathrm{km}$ (the saturated adiabatic lapse rate, i.e. the maximum moisture adiabatic lapse rate) (Rolland 2003). Comparatively, the estimates of base $G_{\mathrm{ALT}}$ $\left[-4.88( \pm 0.94){ }^{\circ} \mathrm{C}\right.$ per $\left.\mathrm{km}\right]$ on global scale and the averaged $G_{\mathrm{ALT}}\left[-5.00( \pm 1.38){ }^{\circ} \mathrm{C}\right.$ per $\left.\mathrm{km}\right]$ for the high-elevation regions as a whole are close to the maximum value of moisture adiabatic lapse rate rather than the value of dry adiabatic lapse rate. This suggests that the altitude effect, and hence the warming amplification within the high-elevation regions are most likely associated with the effective moist convection. Quantitatively, based on the regression equation between altitude warming rate $(y)$ and altitude (x) established for each region (Fig. 4), the altitude warming rate $\left(Q_{\mathrm{ALT}}\right)$ at the highest observation site (Table 1) can be easily estimated. For instance, it is 1.26 , 0.78 and $0.24{ }^{\circ} \mathrm{C}$ for the Tibetan Plateau, Alps and South American Andes, respectively. Furthermore, if the equation is still robust at the highest point of each region, the $Q_{\mathrm{ALT}}$ for the Tibetan Plateau, Alps and South American Andes 

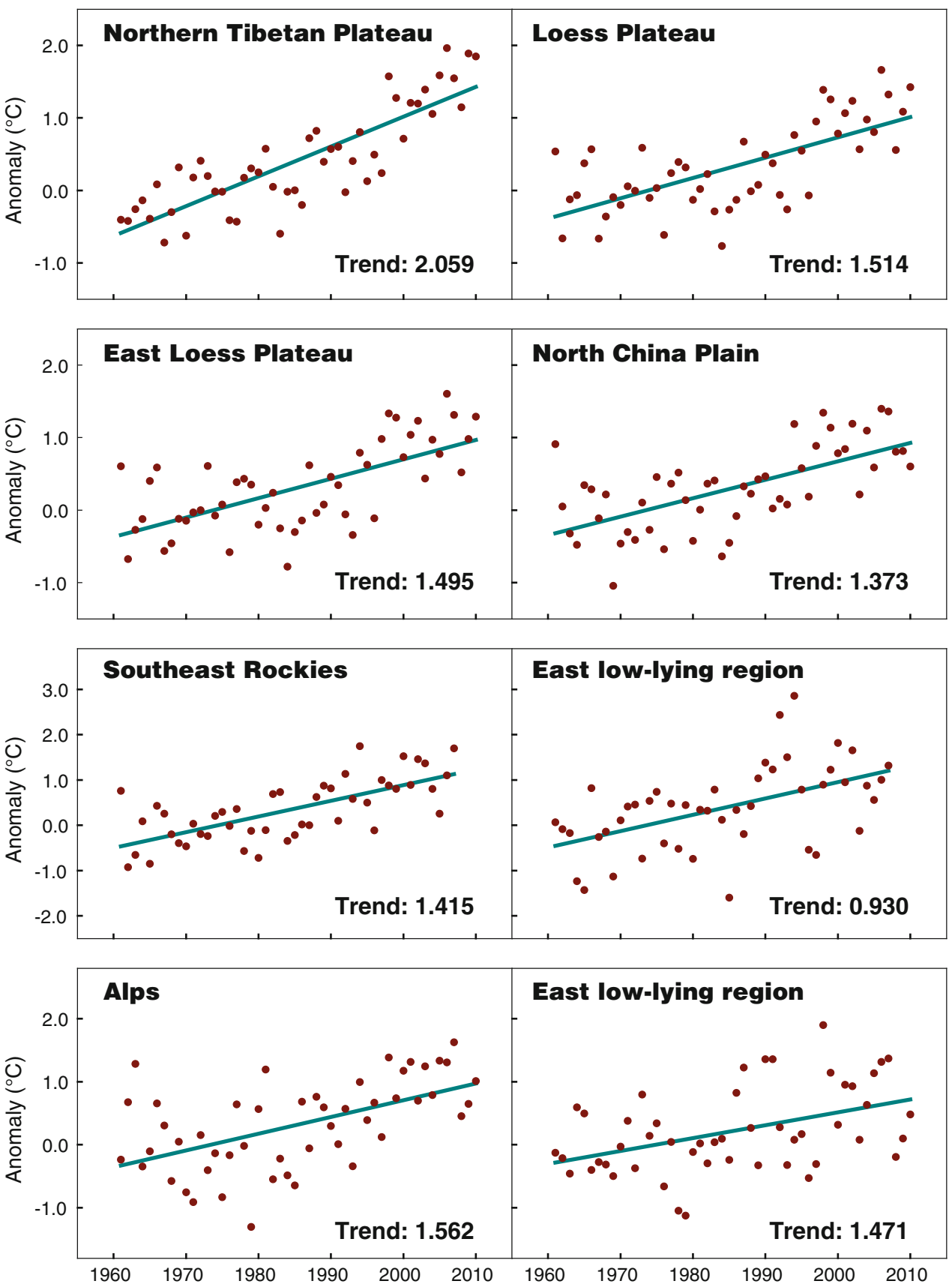

Fig. 5 Monotonic trends of annual mean temperature over the paired regions shown across the globe. Left hand axis shows temperature anomalies relative to the 1961-1990 average. Significant trend, judged using $95 \%$ CI, is set in bold (see Table 6 for details)

will reach $2.38{ }^{\circ} \mathrm{C}$ (at $8.848 \mathrm{~km}$ abs), $1.04{ }^{\circ} \mathrm{C}$ (at $4.810 \mathrm{~km}$ abs) and $1.45{ }^{\circ} \mathrm{C}$ (at $6.962 \mathrm{~km}$ abs), respectively. This kind of signals is of great importance for climate impact assessment. In addition, it should be noted that the $G_{\mathrm{ALT}}$ at the highest point of the Tibetan Plateau or the South American Andes may be close to the dry adiabatic lapse rate with the decrease of temperature, i.e. the altitude effect coefficient $\left(E C_{\mathrm{ALT}}\right)$ could be higher with the increase in altitude. Therefore the $Q_{\mathrm{ALT}}$ could be even greater than
2.38 or $1.45^{\circ} \mathrm{C}$ in the highest area of the Tibetan Plateau or the South American Andes theoretically.

Compared with the base latitude temperature gradient $\left[-0.55( \pm 0.41)^{\circ} \mathrm{C}\right.$ per degree $]$ on global scale, the averaged latitude temperature gradient $\left[-0.81( \pm 0.19){ }^{\circ} \mathrm{C}\right.$ per degree] for the high-elevation regions is much smaller, indicating an enhancing effect of altitude on the decrease of latitude temperature gradient in these regions. Therefore a generally larger latitude effect coefficient should exist in 
Table 6 Monotonic trends of annual mean temperature in the paired regions

\begin{tabular}{|c|c|c|c|c|c|c|c|}
\hline \multirow[t]{2}{*}{ No. } & \multirow[t]{2}{*}{ Paired regions } & \multicolumn{2}{|c|}{ Mann-Kendall trend test } & \multirow[t]{2}{*}{ Latitude } & \multirow[t]{2}{*}{ Longitude } & \multirow[t]{2}{*}{ Average Elev. $(\mathrm{km})$} & \multirow[t]{2}{*}{$\mathrm{n}$} \\
\hline & & $Z$ & $Q_{\text {TOTAL }}$ & & & & \\
\hline \multirow[t]{2}{*}{1} & North Tibetan Plateau (sampled) & $5.663(p<0.001)$ & 2.095 & $34-38^{\circ} \mathrm{N}$ & $93-102^{\circ} \mathrm{E}$ & 3.1365 & 23 \\
\hline & Loess Plateau (sampled) & $4.250(p<0.001)$ & 1.514 & $34-38^{\circ} \mathrm{N}$ & $103-112^{\circ} \mathrm{E}$ & 1.0452 & 119 \\
\hline \multirow[t]{2}{*}{2} & East Loess Plateau & $4.215(p<0.001)$ & 1.495 & $34-38^{\circ} \mathrm{N}$ & $107-112^{\circ} \mathrm{E}$ & 0.7992 & 85 \\
\hline & North China Plain & $4.525(p<0.001)$ & 1.373 & $34-38^{\circ} \mathrm{N}$ & $114-119^{\circ} \mathrm{E}$ & 0.0772 & 17 \\
\hline \multirow[t]{2}{*}{3} & Southeast Rockies (USA) & $3.474(p<0.001)$ & 1.415 & $36-41^{\circ} \mathrm{N}$ & $104-109^{\circ} \mathrm{W}$ & 2.0733 & 16 \\
\hline & East lower region of SE Rockies & $2.301(p=0.021)$ & 0.930 & $36-41^{\circ} \mathrm{N}$ & $86-91^{\circ} \mathrm{W}$ & 0.1772 & 52 \\
\hline \multirow[t]{2}{*}{4} & Alps & $4.465(p<0.001)$ & 1.639 & $45-48.5^{\circ} \mathrm{N}$ & $5.5-16.5^{\circ} \mathrm{E}$ & 1.0501 & 70 \\
\hline & East lower region of Alps & $3.362(p<0.001)$ & 1.471 & $45-48.5^{\circ} \mathrm{N}$ & $17^{\circ} \mathrm{E}-28^{\circ} \mathrm{E}$ & 0.2045 & 13 \\
\hline
\end{tabular}

Each of the paired regions, selected using the belt transect method, are located at the same latitudes, with the same longitude ranges. The areas of first two paired regions are different from the exact areas of these regions. The 50-year trends (1961-2010) are given for first three pairs of regions, while the 47-year trends (1961-2007) are shown for the fourth pair of regions due to lack of data for the most recent 3 years in the HISTALP (http://www.zamg.ac.at/histalp). Two tailed $p$ values are given, and the significant trends, judged using $95 \%$ CI, are set in bold

Table 7 Mean temperature and temperature trends within the Tibetan Plateau (TP), Loess Plateau (LP), Northern Polar Area (North of $\left.60^{\circ} \mathrm{N} ; \mathrm{NPA}\right)$ and High Latitude Area $\left(55-60^{\circ} \mathrm{N}\right.$; HLA) during 1961-2010

\begin{tabular}{lrrrrrr}
\hline Region & Annual & Winter & Spring & Summer & Autumn & \multicolumn{1}{c}{$\mathrm{n}$} \\
\hline \multicolumn{7}{c}{ Mean temperature $\left({ }^{\circ} \mathrm{C}\right)$} \\
TP & 1.608 & -9.051 & 2.212 & 11.271 & 2.001 & 66 \\
LP & 9.074 & -4.313 & 10.134 & 21.273 & 9.202 & 196 \\
NPA & -1.952 & -16.026 & -4.374 & 11.186 & 1.406 & 85 \\
HLA & 3.212 & -8.702 & 1.933 & 14.048 & 5.567 & 48 \\
7 TP & Trend $\left({ }^{\circ}\right.$ C per 50 years) & & & \\
LP & $\mathbf{1 . 8 6 7}$ & $\mathbf{3 . 0 2 0}$ & $\mathbf{1 . 3 9 6}$ & $\mathbf{1 . 3 5 6}$ & $\mathbf{1 . 8 9 8}$ & 66 \\
NPA & $\mathbf{1 . 5 9 5}$ & $\mathbf{2 . 8 2 7}$ & $\mathbf{1 . 7 6 8}$ & 0.638 & $\mathbf{1 . 1 4 6}$ & 196 \\
HLA & $\mathbf{1 . 6 3 8}$ & $\mathbf{2 . 3 3 6}$ & $\mathbf{1 . 8 6 1}$ & $\mathbf{1 . 1 4 3}$ & $\mathbf{1 . 2 4 0}$ & 48 \\
\hline
\end{tabular}

The significant trends, judged using $95 \% \mathrm{CI}$, are set in bold

a high-elevation region relative to its low lying counterpart(s). Since the larger latitude effect coefficient can lead to a greater latitudinal warming rate (i.e. a latitudinal amplification) and the increase of station total warming rate at the same time, the greater warming in a high-elevation region relative to its lower elevation counterpart(s) can be attributed to not only the altitude amplification but also the latitude amplification.

The warming of $1.87{ }^{\circ} \mathrm{C}$ per 50 years in the Tibetan Plateau is the greatest among the eight high-elevation regions, though second to the warming of $2.23{ }^{\circ} \mathrm{C}$ per 50 years in the Northern Polar Area (Table 7), the greatest warming at the higher northern latitudes. However despite some apparent differences between the Tibetan Plateau and Northern Polar Area in terms of the patterns of seasonal warming (Table 7), and the percentages of warming components for altitude, latitude and longitude (Table 5), there exists an essential similarity between them: the greatest (weakest) seasonal warming coincides exactly with the lowest (highest) seasonal mean temperature (Table 7). The analysis of correlation between the temperature anomalies (1961-2010) further reveals that while a highly significant correlation is found between the Tibetan Plateau and Northern Polar Area, the significant correlation is also detected between the Tibetan Plateau and Loess Plateau (LP), and the Northern Polar Area and the High Latitude Area (Table 8). This suggests that the warming amplification in the Tibetan Plateau (the Northern Polar Area) could be an extension of the temperature increase of the neighboring lower altitude (latitude) region rather than mediated by local processes. We speculate that the air temperature gradient, which exists between the surface and the atmosphere, and between the equator and northern polar area is the common driving force leading to the Tibetan Plateau (Arctic) amplification. While the interaction between equator-to-pole air temperature gradient and poleward atmospheric heat transport may have played a major role in leading to the Arctic amplification (Graversen et al. 2008; Bekryaev et al. 2010), the interaction between the surface-atmosphere gradient and upward heat transport has likely played a substantial part in causing the Tibetan Plateau amplification. At the same time, it should be noted that other mechanisms may have also made some contribution in causing the amplification on regional scale (Graversen et al. 2008; Screen and Simmonds 2010; Serreze and Barry 2011) and the snow and ice feedbacks might become the dominant mechanism for a future Arctic amplification (Graversen et al. 2008) or Tibetan Plateau amplification.

The altitudinal amplification is a common feature of the high-elevation regions across the globe. However it does not imply that this phenomenon occurs across all highelevation regions on the earth. It is likely that if the signal- 
Table 8 Correlation between temperature anomalies (1961-2010) for each pair of regions

\begin{tabular}{llllll}
\hline Region $^{\mathrm{a}}$ & Annual & Winter & Spring & Summer & \multicolumn{1}{c}{ Autumn } \\
\hline TP versus LP & $\mathbf{0 . 7 4 4}$ & $\mathbf{0 . 5 4 5}$ & $\mathbf{0 . 4 5 7}$ & $\mathbf{0 . 3 1 8}$ & $(p=0.024)$ \\
& $(p<0.001)$ & $(p<0.001)$ & $(p<0.001)$ & $\mathbf{0 . 3 7 8}$ \\
TP versus NPA & $\mathbf{0 . 7 0 8}$ & $\mathbf{0 . 4 9 2}$ & $(p=0.007)$ \\
TP versus HLA & $(p<0.001)$ & $(p<0.001)$ & $(p=0.001)$ & $(p<0.001)$ & $\mathbf{0 . 3 7 5}$ \\
& $\mathbf{0 . 4 1 0}$ & $\mathbf{0 . 3 4 8}$ & $\mathbf{0 . 3 5 1}$ & $\mathbf{0 . 5 1 1}$ & $(p=0.007)$ \\
LP versus NPA & $(p=0.003)$ & $(p=0.013)$ & $(p=0.012)$ & $0.001)$ & $(p=0.090)$ \\
& $\mathbf{0 . 5 8 4}$ & 0.267 & 0.248 & $(p=0.001)$ & $\mathbf{0 . 4 5 3}$ \\
LP versus HLA & $(p<0.001)$ & $(p=0.061)$ & $(p=0.083)$ & $\mathbf{0 . 4 3 5}$ & $(p<0.001)$ \\
NPA versus HLA & $\mathbf{0 . 4 3 6}$ & $\mathbf{0 . 2 8 9}$ & $(p=0.003)$ & $0.002)$ & $(p=0.104)$ \\
& $(p=0.002)$ & $(p=0.042)$ & $\mathbf{0 . 4 1 5}$ & $\mathbf{0 . 8 7 8}$ & $(p<0.001)$ \\
\hline
\end{tabular}

a Same as in Table 7. The anomalies were calculated relative the 1961 to 1990 average. Pearson correlation coefficients are shown with two tailed $p$ values in parentheses. The significant coefficients, judged using $95 \% \mathrm{CI}$, are set in bold

to-noise ratio is not big enough, then the altitudinal amplification would be undetectable. The signal from altitude effect can be contaminated by the noise from specific factors such as temperature inversion (Beniston and Rebetez 1996; Ohmura 2012) and urbanization effect (Pepin and Lundquist 2008; Ren et al. 2008) characteristic of low elevation stations. Similarly, the high-elevation region does not always have a faster warming than its lower counterpart. This can also be attributable to multiple factors, especially the higher urban and industrial effect at low-altitude locations (Pepin and Lundquist 2008). For instance, if the lower region is more strongly affected by such an effect, leading to an additional increase of 0.35 and $0.80{ }^{\circ} \mathrm{C}$ per 50 years (Ren et al. 2008) for the high and lower elevation regions, respectively, then the same or even faster warming may be detected in the lower region. However, these cases can not offset the common occurrence of warming amplification in the high-elevation regions. Therefore the warming amplification in the highelevation regions is an intrinsic feature of global warming in recent decades.

\section{Conclusions}

In the present study, particular focus has been given to the development of the function equations for the extraction of warming components of altitude, latitude and longitude from the total warming rates at individual stations within a high-elevation region. This is primarily due to that if the total warming rates are directly used for analysis, altitude amplification can hardly be detected in any high-elevation region. The separation of altitudinal warming rates from the total warming rates at individual stations is a prerequisite for the precise analysis of altitudinal amplification within a high-elevation region.

With the new equation(s), we have performed the extraction of altitudinal (latitudinal or longitudinal) warming rate from total warming rate for every station within each region. As a result, a significant trend of altitudinal amplification is found for the eight high-elevation regions tested. The 50-year trend of $0.19( \pm 0.09){ }^{\circ} \mathrm{C}$ per $\mathrm{km}$ of altitude is observed for these regions as a whole, and the relative contributions of altitude, latitude and longitude account for $13.5( \pm 7.8) \%, 72.9( \pm 23.4) \%$ and 13.6 $( \pm 20.9) \%$, respectively. This indicates that the surface mean temperature lapse rate has decreased at a rate of about $0.2{ }^{\circ} \mathrm{C}$ per $\mathrm{km}$ over the last 50 years. The greater latitudinal effect compared with the altitudinal effect confirms that the positive or negative SCOALLA could have substantial effect on the altitudinal dependence of the station warming rates.

The paired region comparison shows that the warming for the sampled North Tibetan Plateau, East Loess Plateau, Southeast Rockies and Alps is clearly greater than their low-lying counterparts. The warming for the sampled North Tibetan Plateau is also much greater than the North China Plain at the same latitudes. This indicates that the warming in a high-elevation region is usually greater than its lower elevation counterpart(s) at the same latitudes.

Comparatively, the averaged altitude temperature gradient for the high-elevation regions is close to the moist adiabatic lapse rate rather than the dry adiabatic lapse rate. This suggests that the altitude effect, and hence the warming amplification within these regions are most likely associated with the effective moist convection. The smaller latitude temperature gradient for these regions indicates an enhancing effect of altitude on the decrease of latitude 
temperature gradient, and hence a generally larger latitude effect coefficient in a high-elevation region relative to its low lying counterpart(s). Therefore the greater warming in the high-elevation region can be attributed to not only the altitude amplification but also the latitude amplification. The results of this study suggest that warming amplification in high-elevation regions is an intrinsic feature of recent global warming.

Acknowledgments We thank Dr. Roger Gifford (CSIRO) for useful comments on the manuscript. We thank the anonymous reviewers. This study is funded by the National Natural Science Foundation of China and the Shanxi Scholarship Council of China.

Open Access This article is distributed under the terms of the Creative Commons Attribution License which permits any use, distribution, and reproduction in any medium, provided the original author(s) and the source are credited.

\section{References}

Appenzeller C, Begert M, Zenklusen E, Scherrer SC (2008) Monitoring climate at Jungfraujoch in the high Swiss Alpine region. Sci Tot Env 391:262-268

Auer I, Jurkovic A, Orlik A, Böhm R, Korus E, Sulis A, Marchetti A, Manenti C, Dolinar M, Nadbath M, Vertacnik G, Vicar Z, Pavcic B, Geier G, Rossi G, Leichtfried A, Schellander H, Gabl K, Zardi D (2008) High quality climate data for the assessment of Alpine climate, its variability and change on regional scalecollection and analysis of historical climatological data and metadata. Final Report FORALPS WP5: meteo-hydrological forecast and observations for improved water resource management in the Alps WP 5 Data Set

Bekryaev RV, Polyakov IV, Alexeev VA (2010) Role of polar amplification in long-term surface air temperature variations and modern Arctic warming. J Clim 23:3888-3906

Beniston M (2003) Climatic change in mountain regions: a review of possible impacts. Clim Chang 59:5-31

Beniston M, Rebetez M (1996) Regional behavior of minimum temperatures in Switzerland for the period 1979-1993. Theor Appl Climatol 53:231-243

Beniston M, Diaz H, Bradley R (1997) Climatic change at high elevation sites: an overview. Clim Chang 36:233-251

Bradley RS, Keimig FT, Diaz HF, Hardy DR (2009) Recent changes in freezing level heights in the Tropics with implications for the deglacierization of high mountain regions. Geophys Res Lett 36:L17701. doi:10.1029/2009GL037712

Chen B, Chao W, Liu X (2003) Enhanced climatic warming in the Tibetan Plateau due to doubling $\mathrm{CO}_{2}$ : a model study. Clim Dyn 20:401-413

Diaz HF, Bradley RS (1997) Temperature variations during the last century at high elevation sites. Clim Chang 36:253-279

Diaz HF, Eischeid JK (2007) Disappearing “alpine tundra” Koppen climatic type in the western United States. Geophys Res Lett 34:L18707. doi:10.1029/2007GL031253

Diaz HF, Eischeid JK, Duncan C, Bradley RS (2003) Variability of freezing levels, melting season indicators, and snow cover for selected high-elevation and continental regions in the last 50 years. Clim Chang 59:33-52

Fan XH, Wang QX, Wang MB (2012) Changes in temperature and precipitation extremes during 1959-2008 in Shanxi, China. Theor Appl Climatol 109:283-303
Fyfe JC, Flato GM (1999) Enhanced climate change and its detection over the Rocky Mountains. J Clim 12:230-243

Giorgi F, Hurrell J, Marinucci M, Beniston M (1997) Elevation dependency of the surface climate change signal: a model study. J Clim 10:288-296

Graversen RG, Mauritsen T, Tjernström M, Källén E, Svensson G (2008) Vertical structure of recent Arctic warming. Nature 541:53-56

Kendall MG (1975) Rank correlation methods. Charles Griffin, London

Kotlarski S, Bosshard T, Lüthi D, Pall P, Schär C (2012) Elevation gradients of European climate change in the regional climate model COSMO-CLM. Clim Chang 112:189-215

Lawrimore JH, Menne MJ, Gleason BE, Williams CN, Wuertz DB, Vose RS, Rennie J (2011) An overview of the Global Historical Climatology Network monthly mean temperature data set, version 3. J Geophys Res 116:D19121. doi:10.1029/ 2011JD016187

Liu X, Chen B (2000) Climate warming in the Tibetan Plateau during recent decades. Int J Climatol 20:1729-1742

Liu X, Hou P (1998) Relationship between the climatic warming over the Qinghai-Xizang Plateau and its surrounding areas in recent 30 years and the elevation. Plateau Meteorology 17(3):245-249 (in Chinese)

Liu X, Cheng Z, Yan L, Yin Z (2009) Elevation dependency of recent and future minimum surface air temperature trends in the Tibetan Plateau and its surroundings. Global Planet Chang 68:164-174

Lu A, Kang S, Li Z, Theakstone W (2010) Altitude effects of climatic variation on Tibetan Plateau and its vicinities. J Earth Sci 21:189-198

Mann HB (1945) Nonparametric tests against trend. Econometrika $13: 245-259$

Ohmura A (2012) Enhanced temperature variability in high-altitude climate change. Theor Appl Climatol 110:499-508

Pepin NC, Losleben ML (2002) Climate change in the Colorado Rocky Mountains: free air versus surface temperature trends. Int J Climatol 22:311-329

Pepin NC, Lundquist JD (2008) Temperature trends at high elevations: patterns across the globe. Geophys Res Lett 35:L14701. doi:10.1029/2008GL034026

Pepin NC, Seidel DJ (2005) A global comparison of surface and free air temperatures at high elevations. J Geophys Res 110:D03104. doi:10.1029/2004JD005047

Rangwala I, Miller JR (2012) Climate change in mountains: a review of elevation-dependent warming and its possible causes. Clim Chang 114:527-547

Ren G, Zhou Y, Chu Z et al (2008) Urbanization effect on observed surface air temperature trend in North China. J Clim 21:1333-1348

Rolland C (2003) Spatial and seasonal variations of air temperature lapse rates in alpine regions. J Clim 16:1032-1046

Santer BD, Wigley TML, Mears C et al (2005) Amplification of surface temperature trends and variability in the tropical atmosphere. Science 309:1551-1556

Screen JA, Simmonds I (2010) The central role of diminishing sea ice in recent Arctic temperature amplification. Nature 464:1334 1337

Seidel D, Free M (2003) Comparison of lower-tropospheric temperature climatologies and trends at low and high elevation radiosonde sites. Clim Chang 59:53-74

Sen PK (1968) Estimates of the regression coefficient based on Kendall's tau. J Am Stat Assoc 63:1379-1389

Serreze MC, Barry RG (2011) Processing and impacts of Arctic amplification: a research synthesis. Global Planet Change 77:85-96 
Snyder M, Bell JL, Sloan LC (2002) Climate responses to a doubling of atmospheric carbon dioxide for a climatically vulnerable region. Geophys Res Lett 29. doi:10.1029/2001GL014431

Solomon S, Qin D, Manning M, Chen Z, Marquis M, Averyt KB, Tignor M, Miller HL (2007) Climate change 2007: the physical science basis. Cambridge University Press, Cambridge

Thorne PW, Lanzante JR, Peterson TC, Seidel DJ, Shine KP (2011) Tropospheric temperature trends: history of an ongoing controversy. WIREs Clim Chang 2:66-88

Vuille M, Bradley RS (2000) Mean annual temperature trends and their vertical structure in the topical Andes. Geophys Res Lett 27:3885-3888

Vuille M, Bradley RS, Werner M, Keimig F (2003) 20th century climate change in the tropical Andes: observations and model results. Clim Chang 59:75-99

Wang XL, Feng Y (2010) RHtestsV3 user manual. http://cccma.seos. uvic.ca/ETCCDMI/RHtest/RHtestsV3_UserManual.doc
Wang XL, Swail VR (2001) Changes of extreme wave heights in Northern Hemisphere oceans and related atmospheric circulation regimes. J Clim 14:2204-2220

Wang QX, Fan XH, Qin ZD, Wang MB (2012) Change trends of temperature and precipitation in the Loess Plateau Region of China, 1961-2010. Global Planet Chang 92-93:138-147

You Q, Kang S, Pepin N, Yan Y (2008) Relationship between trends in temperature extremes and elevation in the eastern and central Tibetan Plateau, 1961-2005. Geophys Res Lett 35:L14704. doi:10.1029/2007GL032669

You Q, Kang S, Pepin N et al (2010) Relationship between temperature trend magnitude, elevation and mean temperature in the Tibetan Plateau from homogenized surface stations and reanalysis data. Global Planet Chang 71(1-2):124-133 